\title{
Tailoring impurity proffle to maximize cavity performance
}

SRF Cavities Dissipation in Surface Nanometric Layer

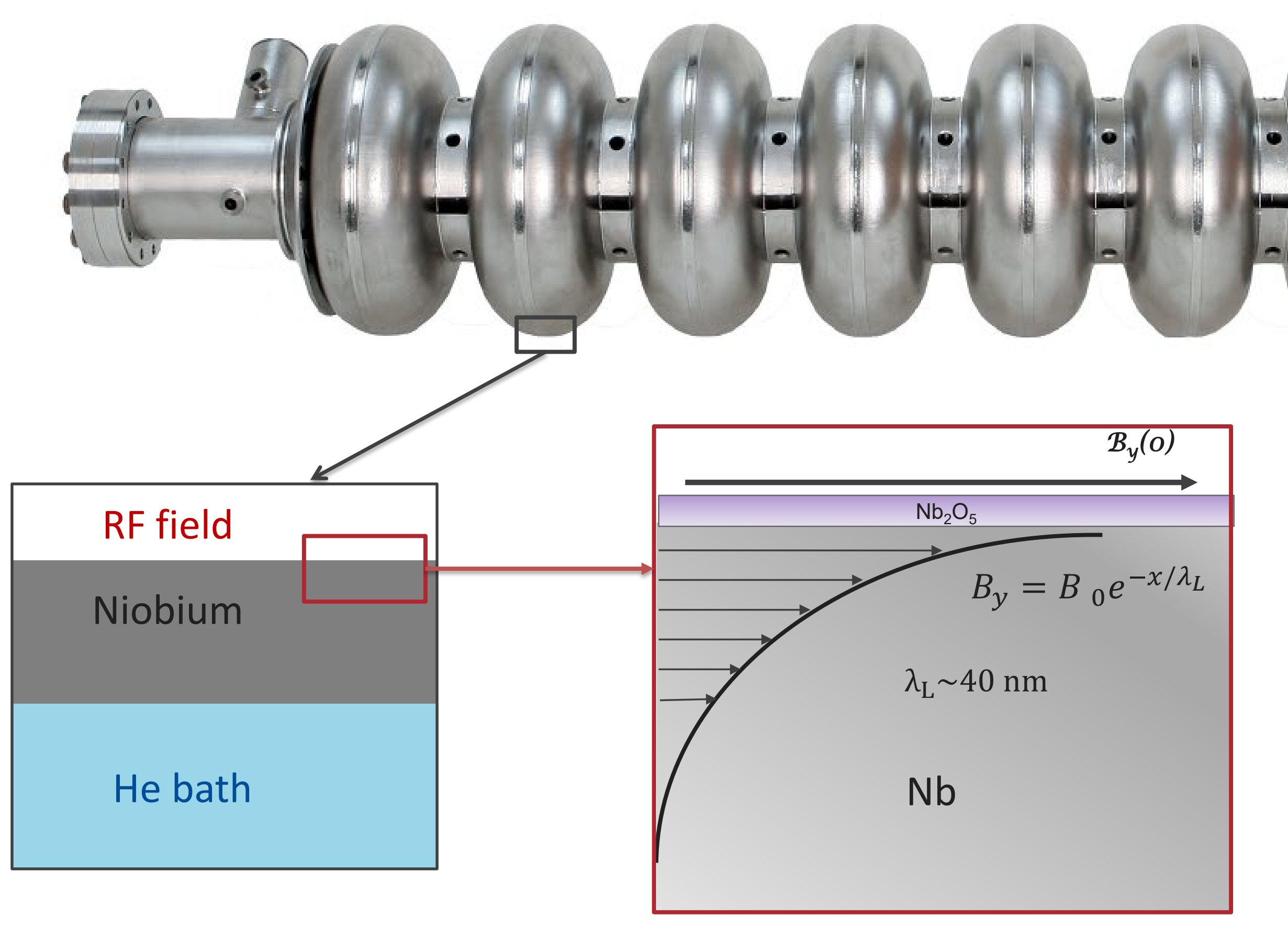

RF dissipation happen in first tens of nanometer of the inner surface.

Final surface treatment is therefore crucial to performance.

\section{Impurity Content Defines SRF Performance}

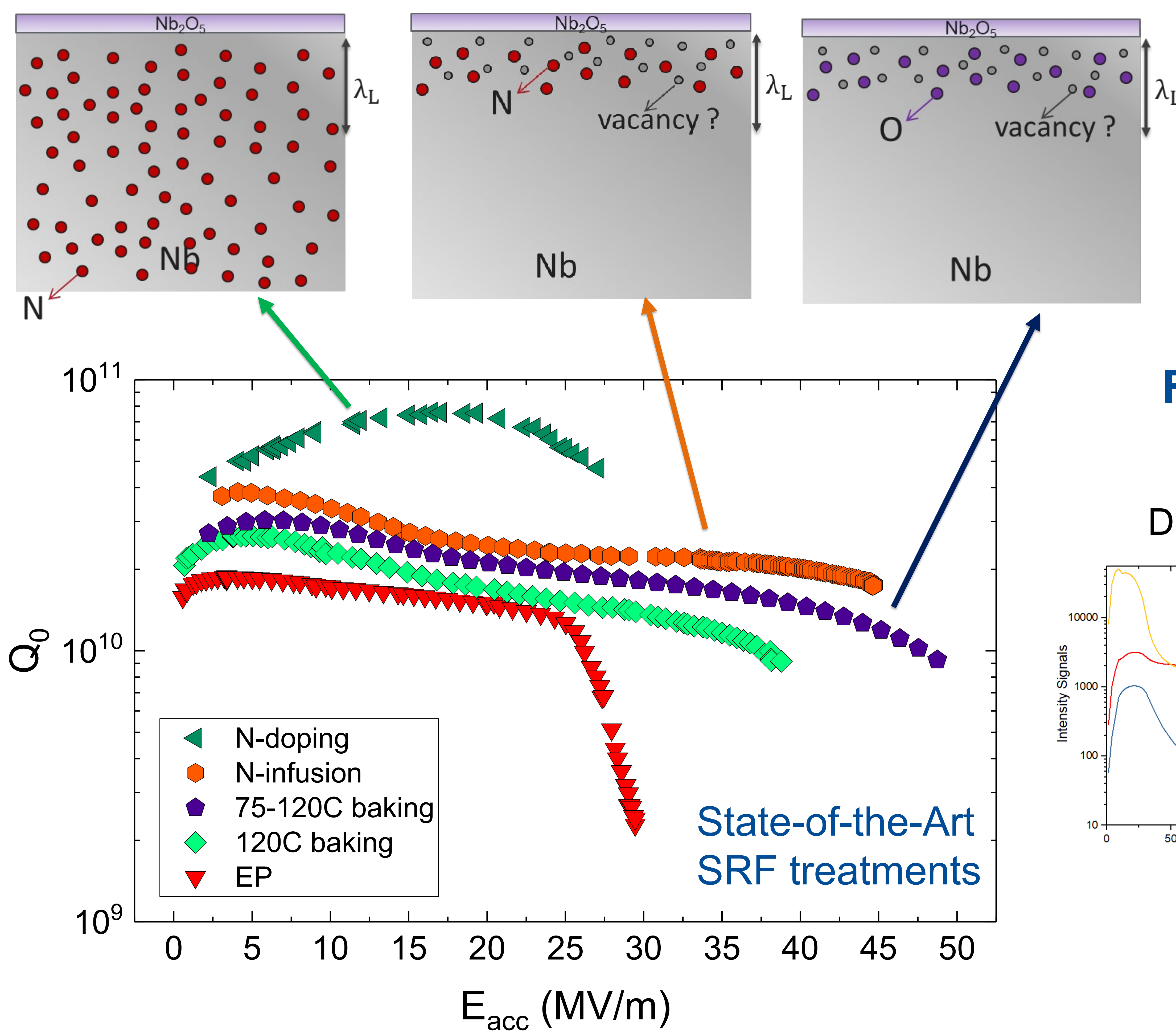

TOF-SIMS to perform detailed elemental analysis

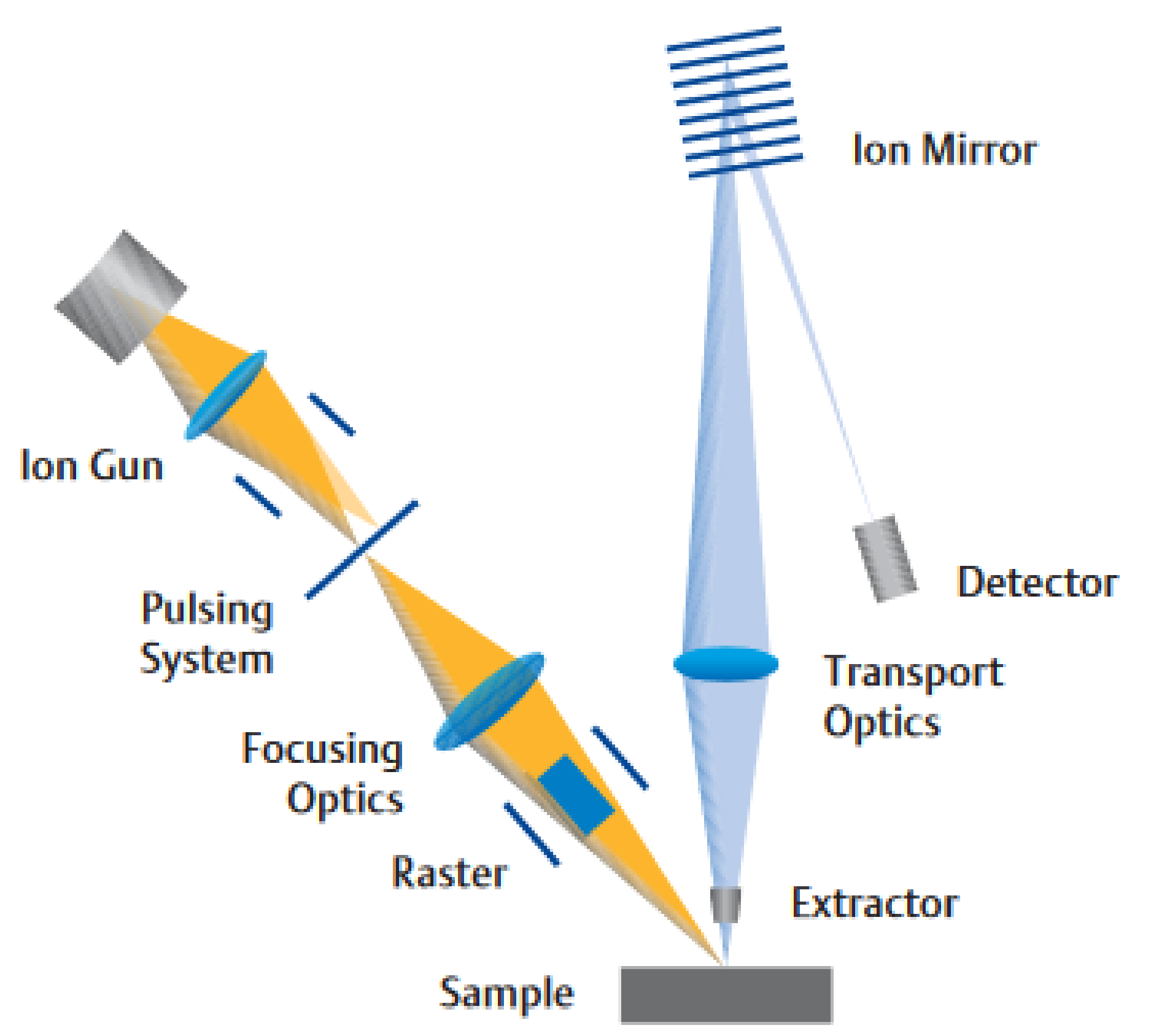

- An ion beam bombards the sample causing ions to be emitted from its surface;

- These ions are extracted and travel through the analysis column to reach the detector;

- The mass of the ions is calculated from their time-offlights.

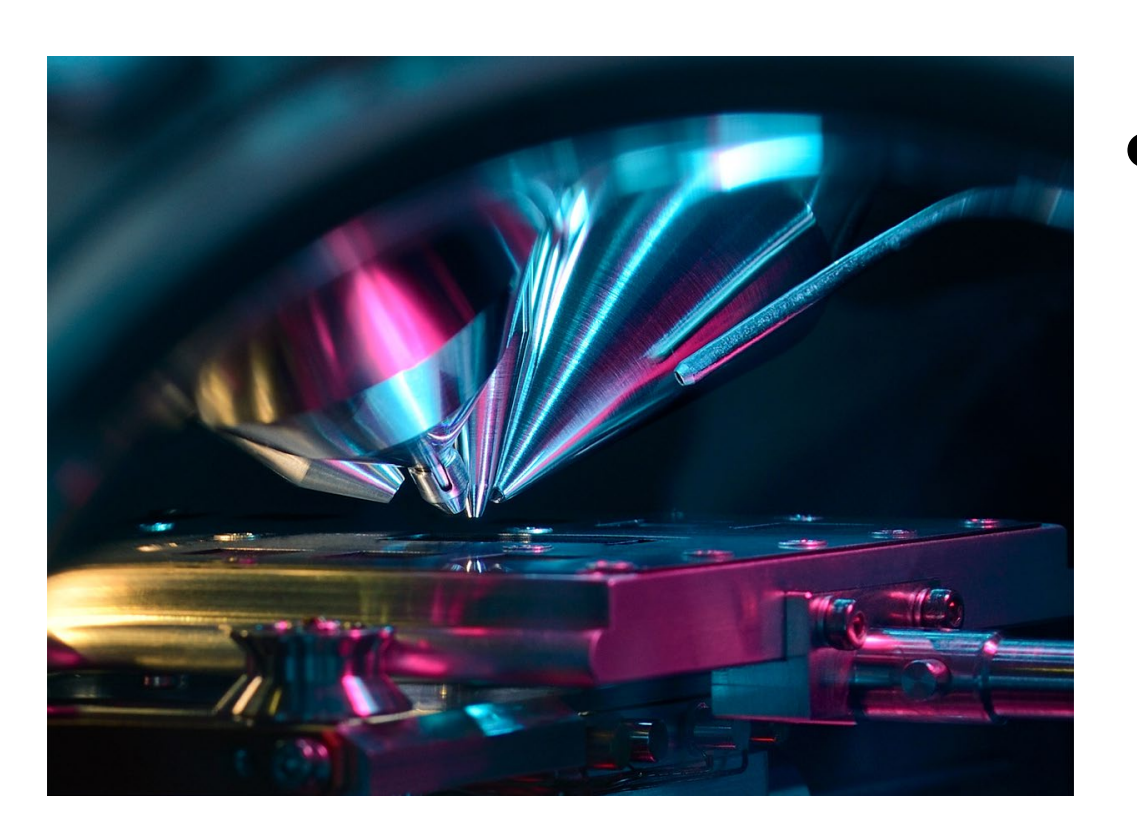

- A primary ion beam (O2 or $\mathrm{Cs}$ ) provides elemental information of the outer monolayers $\rightarrow$ surface spectroscopy and surface imaging;

- Dual Beam Mode: the secondary beam is sputtering a crater, the primary beam is progressively analyzing the crater bottom $\rightarrow$ depth profiling and 3D imaging reconstruction.

\section{From depth profile to 3D reconstruction image} Surface images

$3 \mathrm{D}$ reconstruction

Depth profile

Examples of Progress in Understanding Enabled by SIMS Analysis
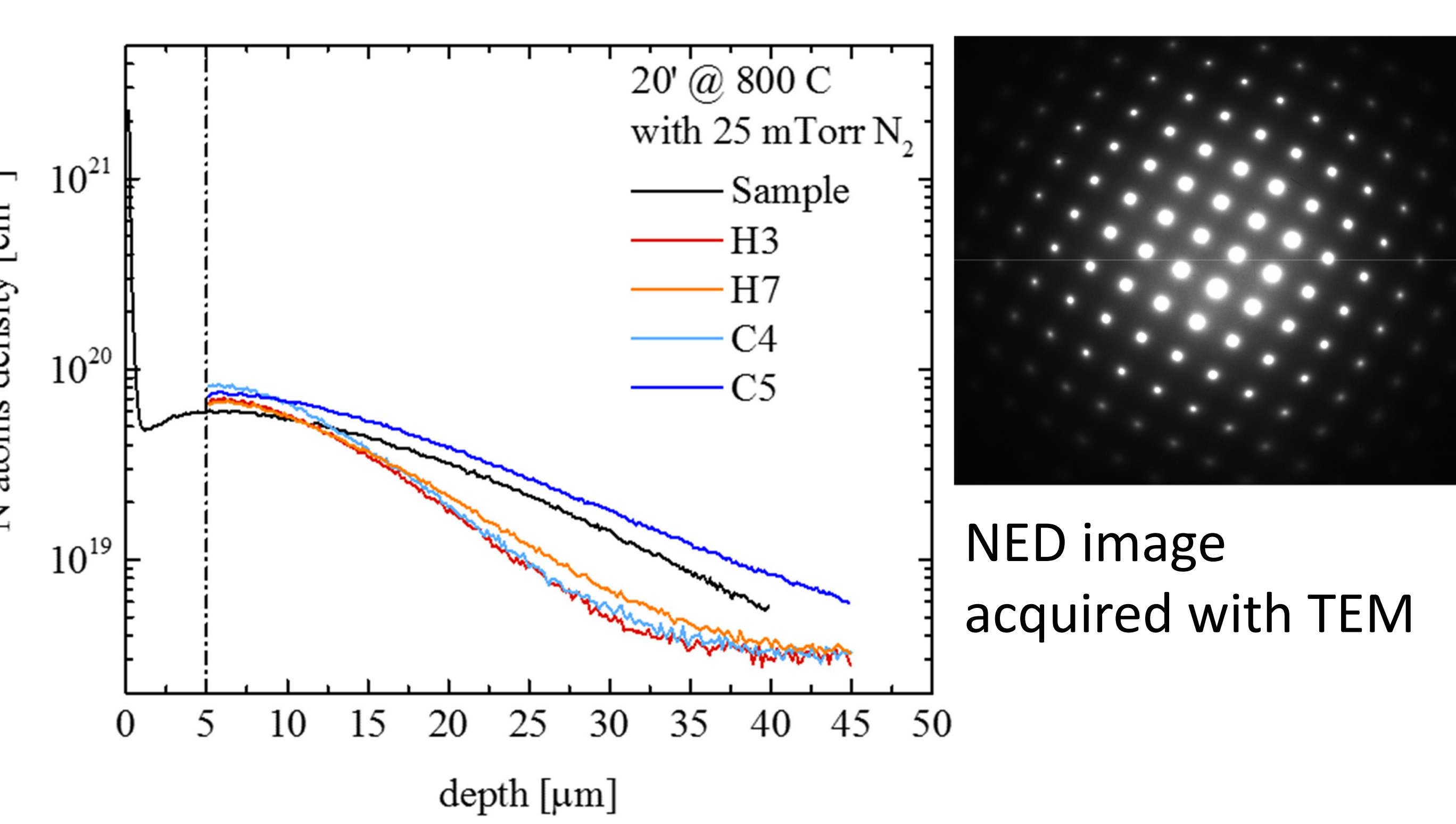

- Nitrogen in the material for about tens of micrometers after $\mathbf{N}$-doping treatment;

- TEM/NED: only $\mathrm{Nb}$ signal from diffraction pattern;

$>$ The two analysis together underline that $\mathrm{N}$ is interstitial after doping treatment!!

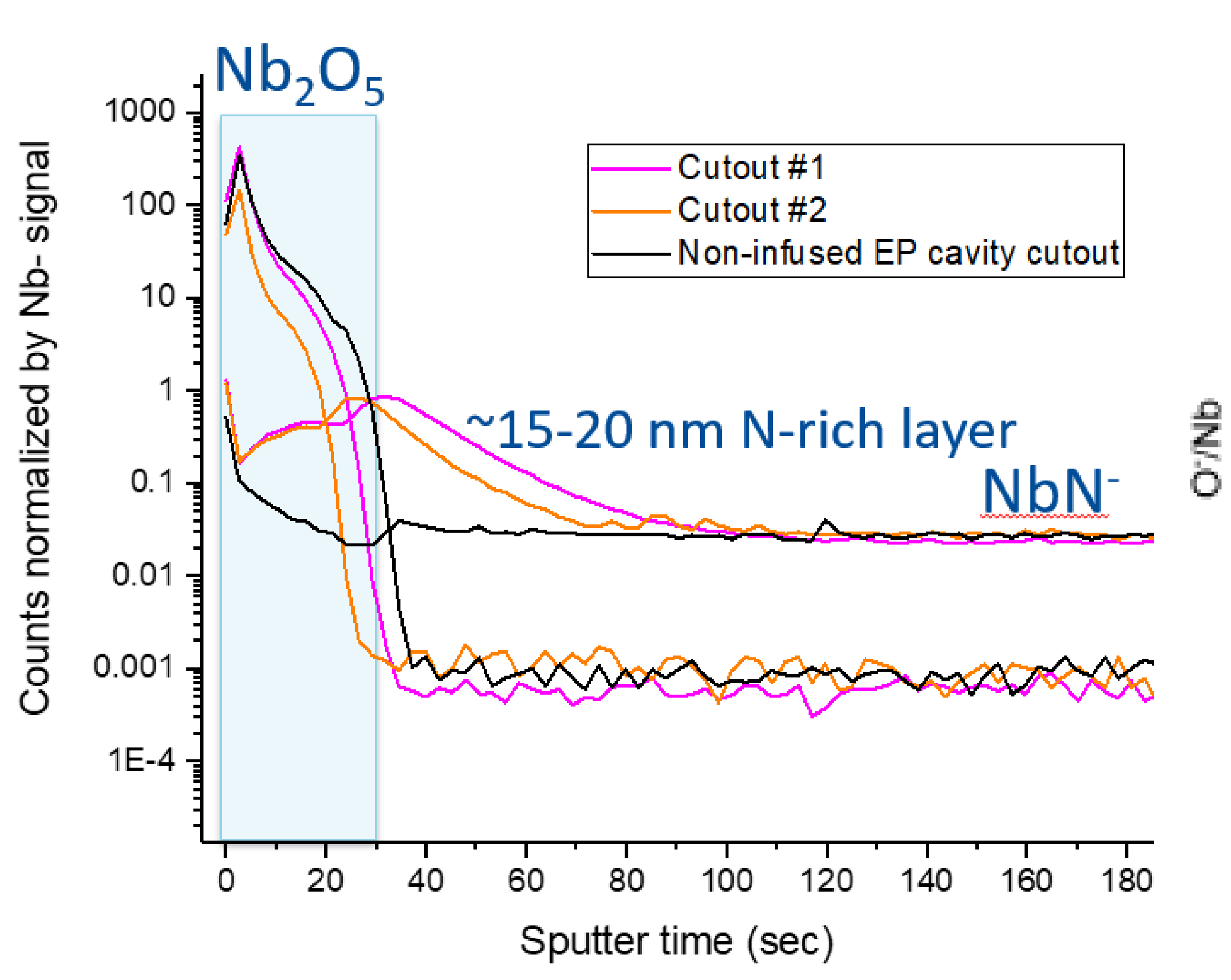

- Nitrogen enriched layer for about 10-15 nanometers below the oxide in $\mathbf{N}$ infused cavities cut-outs.

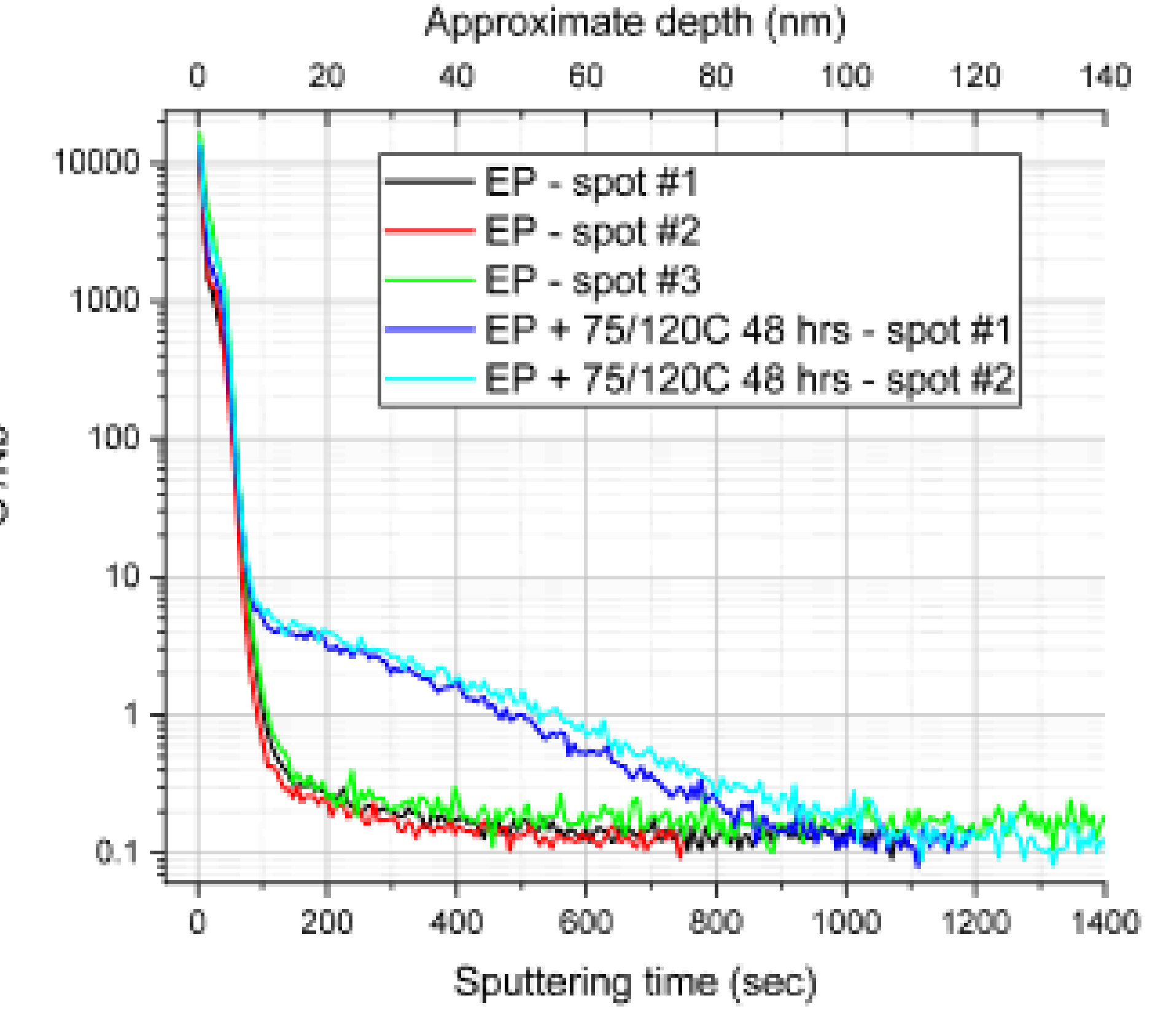

- Oxygen in the material for about tens of nanometers in low-T baked cavity cut-outs.

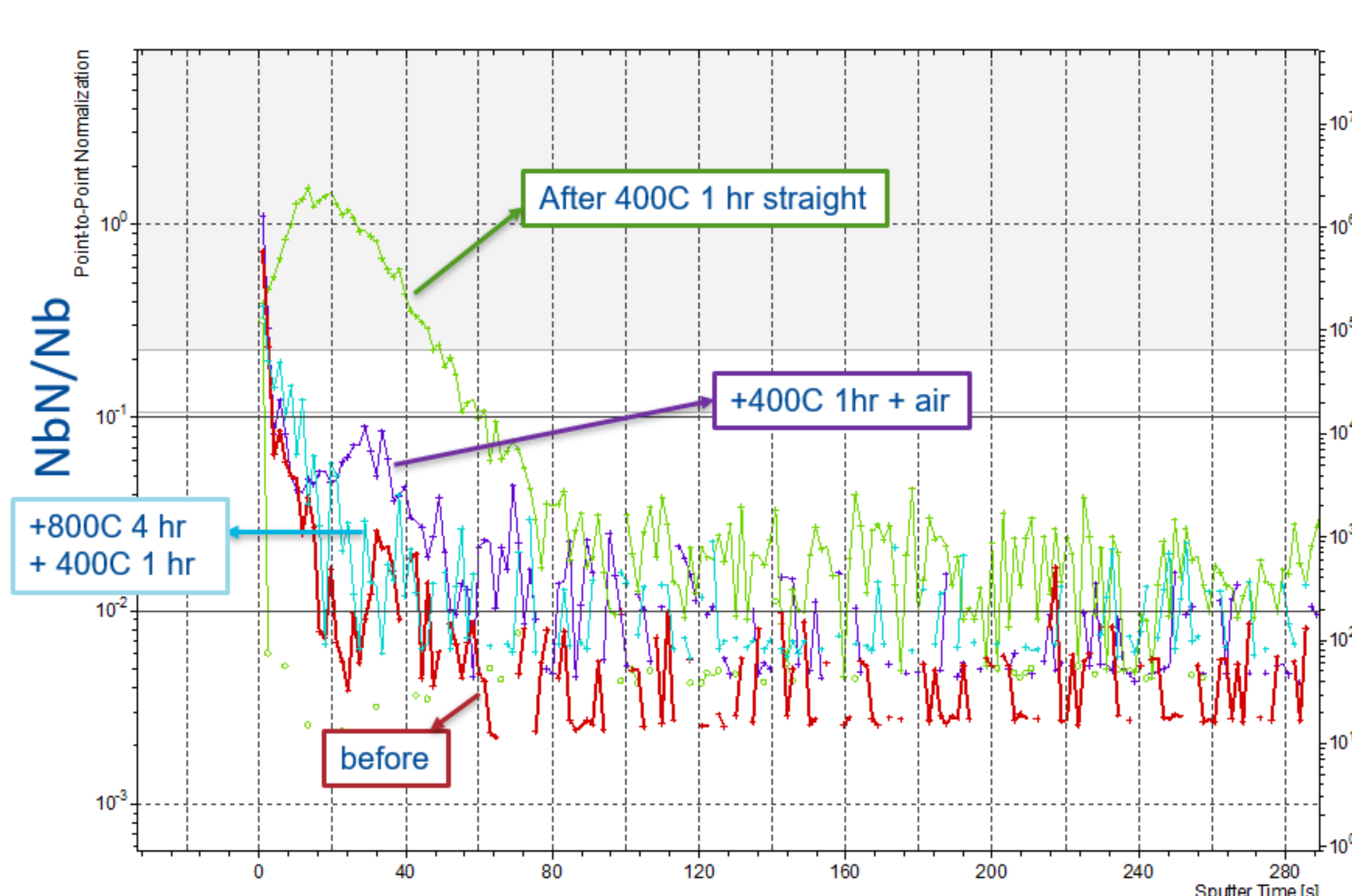

- In-situ SIMS experiments are guiding towards the applications of better heat treatments that lead to SRF cavities with improved performance 